\title{
A First Record of the Genus Parastilomysis (Crustacea: Mysida: Mysidae) from Korea
}

\author{
Mijin Kim¹, Sung Joon Song ${ }^{2}$, Won Kim ${ }^{1, *}$ \\ ${ }^{1}$ School of Biological Sciences, Seoul National University, Seoul 151-747, Korea \\ ${ }^{2}$ Research Institute of Oceanography, Seoul National University, Seoul 151-742, Korea
}

\begin{abstract}
A mysid species, Parastilomysis paradoxa Ii, 1936 belonging to the subfamily Mysinae Hansen, 1910 which comprises approximately $90 \%$ of all mysid species, is newly reported from Korean waters. The genus Parastilomysis Ii, 1936 which is also new to Korea, is distinctly different from other genera by having biramous third and fourth pleopods of the male, and telson with an apical cleft. In the present paper, authors provide detailed descriptions and illustrations of $P$. paradoxa based on the specimens collected from the southern coast of the Korean peninsula, and also discuss on the zoogeographical distribution herein. Parastilomysis paradoxa belongs to Mysidae Haworth, 1825, and is the 50th species in Korea.
\end{abstract}

Keywords: taxonomy, Mysida, Mysidae, Parastilomysis paradoxa, Korea

\section{INTRODUCTION}

The subfamily Mysinae Hansen, 1910 is the most speciose group in family Mysidae Haworth, 1825 and more than 90 percent of the mysid species are distributed worldwide (Tattersall and Tattersall, 1951). The mysinae species is defined by a combination of characters: 1) pleopods of the male variously modified, usually rudimentary in the female, 2) uropod segment undivided, and 3) endopod shorter than exopod.

Up to date 32 species of 14 genera in this subfamily have been reported from Korean waters. During the investigation of the mysid fauna from the southern part of Korea, Parastilomysis paradoxa Ii, 1936 was collected using a light trap in a shallow subtidal area. Parastilomysis paradoxa has been reported from only Japan (Ii, 1936, 1964; Murano, 1970a, 1970b; Fukuoka et al., 2005) and China (Wang and Liu, 1997; Liu and Wang, 2000; Fukuoka et al., 2005). In the present paper, we expand the distribution ranges to Korea and provide a description with illustrations of $P$. paradoxa as the first record to Korean fauna, including the genus as well.

All Specimens were collected with a light trap equipment. Specimens were preserved in $70 \%$ ethyl alcohol and illustra- tions have been prepared using a drawing tube on a compound microscope equipped with differential interference contrast (Model BX-60; Olympus, Tokyo, Japan). Images were recorded using a digital camera (Model D7000; Nikon, Tokyo, Japan), and produced with Helicon Focus software (Model Helicon Focus; Helicon Soft Ltd., Kharkov, Ukraine). Body length was measured from the tip of the rostrum to the distal apex of the telson excluding the spine. The simple setae and plumage of the plumose setae on the margin of antennules, antennae, mouthparts, and uropods are omitted from the figures. Terminology for the dissection and measurement is adopted from Tattersall and Tattersall (1951). All specimens have been deposited in the Marine Arthropod Depository Bank of Korea (MADBK), Seoul National University.

\section{SYSTEMATIC ACCOUNTS}

Order Mysida Haworth, 1825

Family Mysidae Haworth, 1825

Subfamily Mysinae Haworth, 1825

${ }^{1 * G e n u s ~ P a r a s t i l o m y s i s ~ I i, ~} 1936$

Korean name: ${ }^{1 *}$ 두갈래꼬리곤쟁이속(신칭)

(c) This is an Open Access article distributed under the terms of the Creative Commons Attribution Non-Commercial License (http://creativecommons.org/ licenses/by-nc/3.0/) which permits unrestricted non-commercial use, distribution, and reproduction in any medium, provided the original work is properly cited.

pISSN 2234-6953 eISSN 2234-8190
*To whom correspondence should be addressed

Tel: 82-2-880-6695, Fax: 82-2-872-1993

E-mail:wonkim@plaza.snu.ac.kr 


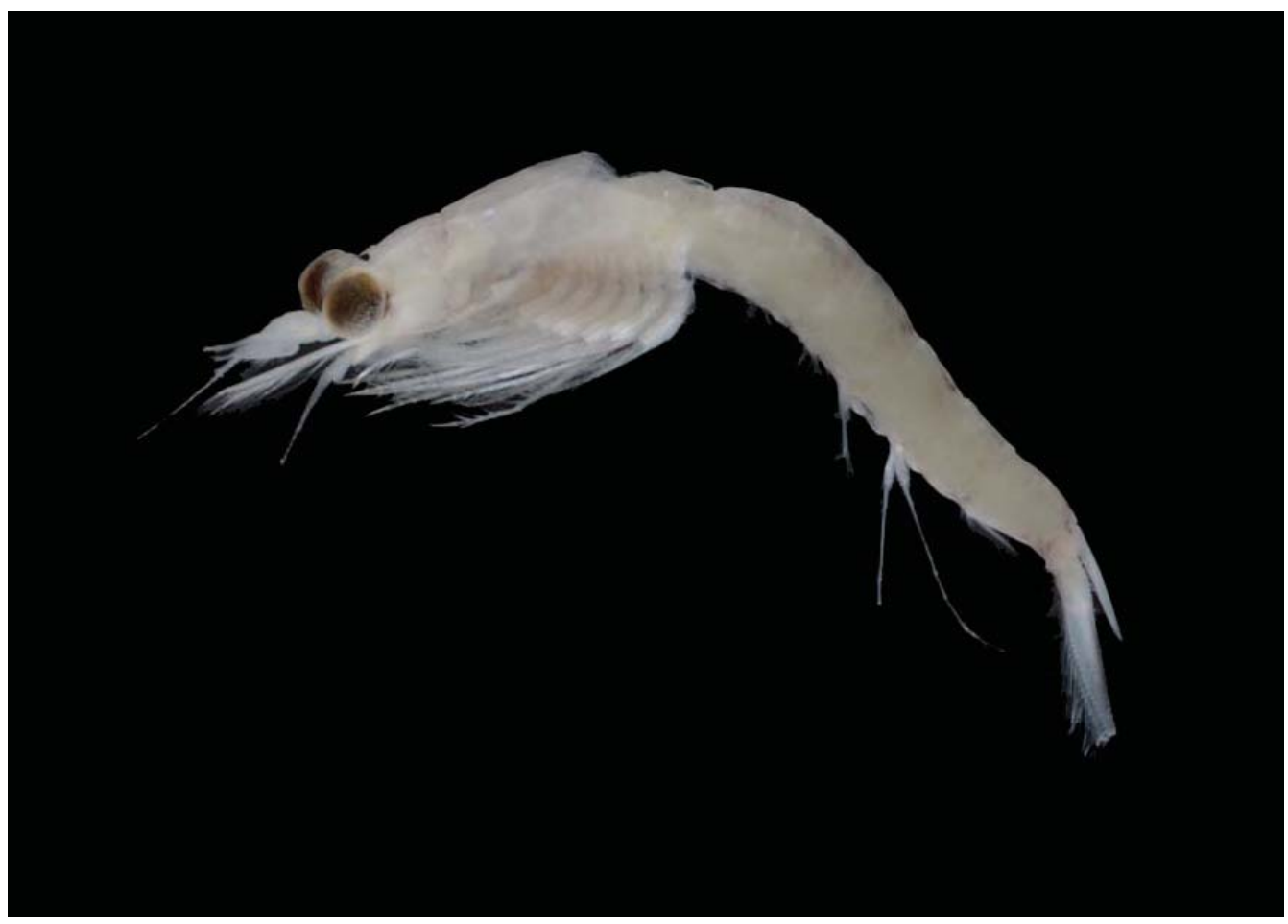

Fig. 1. Parastilomysis paradoxa Ii, 1936, male. Whole animal, $5.4 \mathrm{~mm}$.

\section{1*Parastilomysis paradoxa Ii, 1936 (Figs. 1-4)}

Parastilomysis paradoxa Ii, 1936: 3, figs. 1-14; 1964: 418, fig. 106; Murano, 1970a: 264; 1970b: 146; Mauchline and Murano, 1977: 70; Müller, 1993: 211; Fukuoka et al., 2005: 31 , figs. 1,2 .

Material examined. $1 \sigma^{\nearrow}$, Korea: Gyeongsangnam-do, Geoje-si, Nambu-myeon, Dae-po Port, 20 May 2011, Kim M; $3 \sigma^{\nearrow} \sigma^{\nearrow}$, Jeollanam-do, Yeosu-si, Samsan-myeon, Geomun-ri, Geomundo Isl., Seo-do port, 28 Jul 2011, Kim M.

Description. Carapace (Fig. 2A) with anterior margin produced into rounded rostral plate with blunt tip, reaching base of first segment of antennular peduncle; pseudo-rostral process overlapped below carapace, triangular shape in dorsal view; antero-lateral corners rounded.

Eye (Figs. 1, 2A) large, reaching 1/2 of third segment of antennular peduncle; cornea distinctly reniform, occupying $1 / 2$ of whole eye.

Antennal scale (Fig. 2C) narrow lanceolate with round apex, about 8 times as long as broad; distal suture occupying $1 / 24$ of whole length; all margins armed with setae. Antennal peduncle (Fig. 2C) 3-segmented; second one longest, 1.3 times as long as first and third one.

Antennular peduncle (Fig. 2B) 3-segmented; first segment twice as long as second one, armed with 2 plumose setae on proximal margin; third segments about 1.5 times as long as second one, with developed processus masculinus.

Maxilla and maxillule (Fig. 2D, E) shown no marked difference from those in other species.

Mandibular palp (Fig. 2F) 3-segmented; second segment about 8.5 times as long as first one, and about 2.4 times as long as third one.

Endopod of first and second thoracopods (Fig. 3A, B) showing no marked difference from those in other species.

Endopod of third to eighth thoracopods (Fig. 3C-E) with 3-subsegmented carpopropodus; basal plate of exopod without spinules on outer distal corner except first, second, and eighth thoracopods which armed with one spinule.

First, second and fifth pleopod of male (Fig. 4A, B, D) uniramous, rudimentary and unsegmented.

Third pleopod of male (Fig. 4C) biramous; endopod thick and unsegmented, about 1.6 times as long as exopod; exopod 4-segmented, first one longest and subequal endopod in length, second one about 2/5 times as long as first one, third

Korean name: ${ }^{1 *}$ 두갈래꼬리곤쟁 이 (신칭) 
A
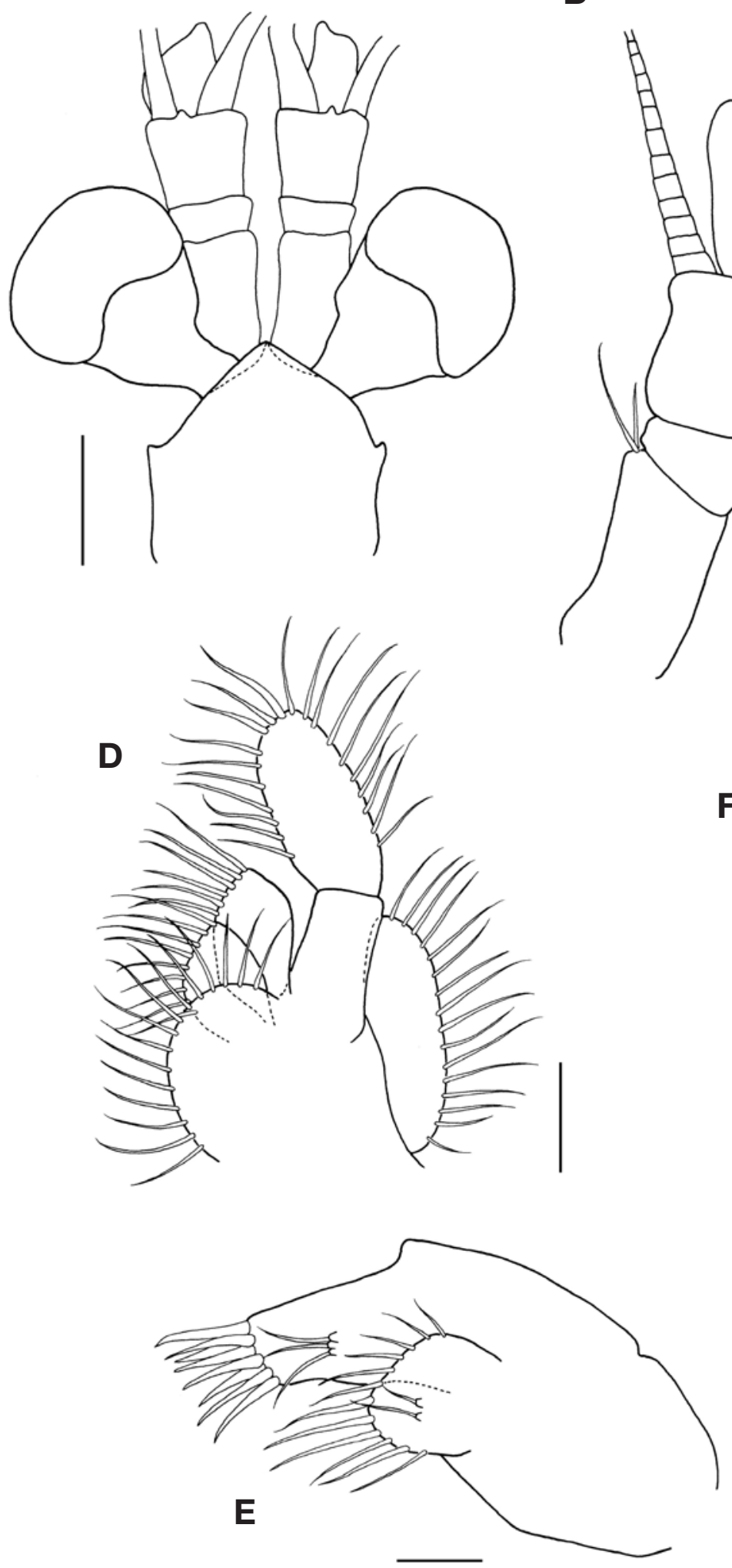

Fig. 2. Parastilomysis paradoxa Ii, 1936, male. A, Anterior part of carapace and cephalic appendages; $B$, Antennule; C, Antenna; $D$ Maxilla; E, Maxillule; $F$, Mandible. Scale bars: $A=1.0 \mathrm{~mm}, B, C=0.5 \mathrm{~mm}, \mathrm{D}, \mathrm{F}=0.2 \mathrm{~mm}, \mathrm{E}=0.1 \mathrm{~mm}$. 


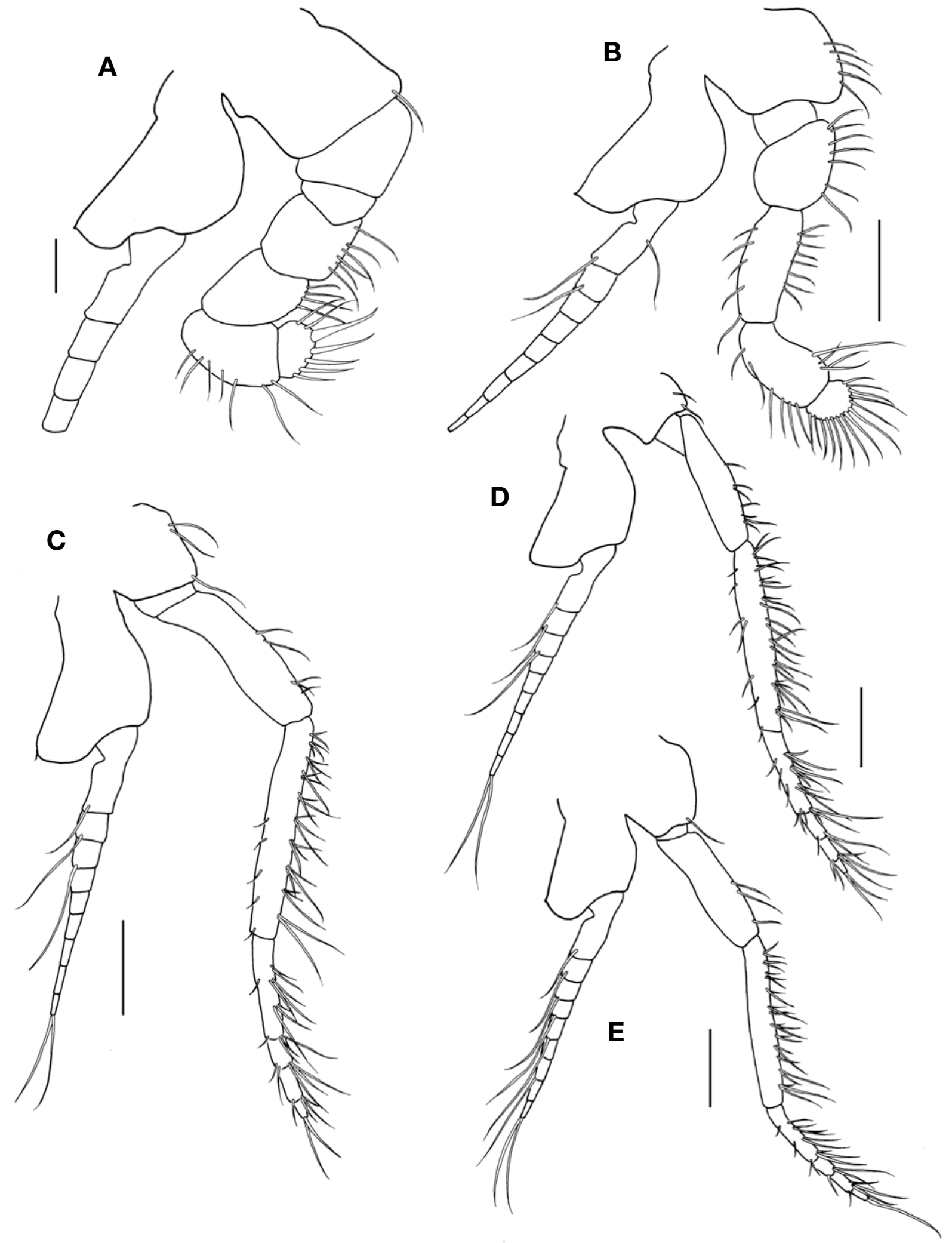

Fig. 3. Parastilomysis paradoxa Ii, 1936, male. A, First thoracopod; B, Second thoracopod; C, Sixth thoracopod; D, Seventh thoracopod; E, Eighth thoracopod. Scale bars: $A, B=0.2 \mathrm{~mm}, C-E=0.5 \mathrm{~mm}$. 


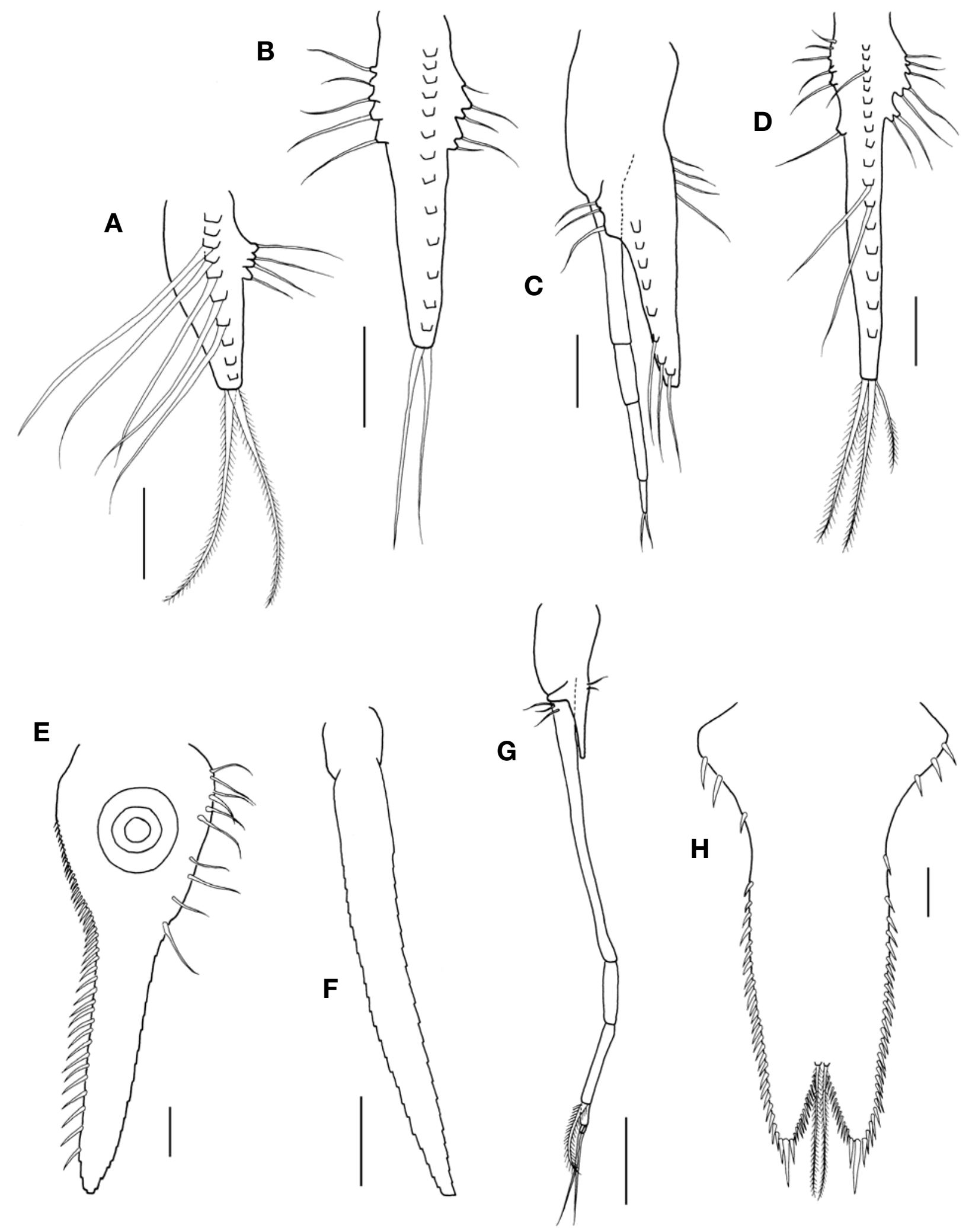

Fig. 4. Parastilomysis paradoxa Ii, 1936, male. A, First pleopod; B, Second pleopod; C, Third pleopod; D, Fifth pleopod; E, Inner uropod; F, Outer uropod; G, Fourth pleopod; $H$, Telson. Scale bars: $A-E, H=0.2 \mathrm{~mm}, F, G=0.5 \mathrm{~mm}$. 
one twice as long as distal one, distal segment terminated by 2 short setae.

Fourth pleopod of male (Fig. 4G) also biramous; endopod small and unsegmented, about 4.2 times as long as exopod; exopod 4-segmented, first one about 2.6 times as long as endopod, second one 1/4 times as long as first one, third one about 1.3 times as long as second one and bearing inwardly curved one strong spinous seta on distal segment, and fourth one 1/4 times as long as third one and terminated by two plumose setae.

Inner uropod (Fig. 4E) bearing about 50 spines in ventral statocyst region, gradually increased in length to distal part; statocyst large and well developed.

Outer uropod (Fig. 4F) about 1.5 times longer than inner one, all margins armed with setae.

Telson (Fig. 4H) broadly linguiform with apical cleft, about 1.7 times as long as basal part; lateral margin of proximal $1 / 3$ armed with 3-4 strong spines, subsequent $1 / 6$ margin naked, remaining region with 25-27 spines tightly; cleft $1 / 6$ times as long as whole length, bearing 15-20 slender spines on entire margin and with one pair of plumose setae in front of anterior end of cleft; each apex truncated and armed with 3 stout spines, medial one longest and robust, and spines on both sides $1 / 2$ times as long as medial one.

Distribution. Korea (the South Sea), Japan (Honshu and Kyushu), China (the East China Sea and Yellow Sea).

Remarks. The examined specimens agree morphologically with the original description of Ii (1936)'s original description in the main characteristics except for the following points: 1) Ii $(1936,1964)$ noted that the basal plate in the exopod of the first to seventh thoracopods has a spinule on the outer distal corner, and the eighth thoracopod has no spinule. On the other hand, the specimens collected from Geomundo Island of Korea do not have any spinules on the exopod of all thoracopods, and another specimen the from same site has a spinule only in first, second, and eighth thoracopods, respectively. 2) there is a variation in the arrangement of spines at the proximal part of the telson. Three individuals have a naked region at the 1/6 part from the base of the telson, while one of the specimens collected from Geomundo Island has no naked region, which is composed of several stout spines subsequently and increased in length distally. This characteristic is consitent with the description of Fukuoka et al. (2005). 3) As to the third pleopod of the male, the first segment of the exopod is slightly shorter than half of the endopod in the previous record (Ii, 1936, 1964). Whereas in the present specimens, the first segment is longer than the half of the endopod, and the endopod is extended beyond the first segment of the exopod.

Parastilomysis paradoxa is a coastal and euryhaline species only distributed in the East Asia: the East China Sea (Wang and Liu, 1997; Liu and Wang, 2000; Fukuoka et al., 2005) and Japanese coastline (Ii, 1936, 1964; Murano, 1970a, 1970b; Fukuoka et al, 2005). Its occurrences between $29^{\circ} \mathrm{N}$ to $38^{\circ} \mathrm{N}$ seem to be subject to the Kuroshio warm current. Accordingly, the present study provides additional zoogeographical distribution in Asian area, and there is a possibility that extends to the east and west coast of Korea through further detailed studies from various habitats. The species was collected from the sea floor at depths of 0-730 $\mathrm{m}$ with several methods of oblique tow, larva net, bottom net, beam trawl, and cruise survey (Fukuoka et al., 2005), which marks a wide vertical distribution.

\section{ACKNOWLEDGMENTS}

The present study was supported by The Survey of Korean Indigenous Species from National Institute of Biological Resources (NIBR) of Ministry of Environment of Korea, and by a grant from Marine Biotechnology Programme funded by Ministry of Land, Transport and Maritime affairs of the Korean Government.

\section{REFERENCES}

Fukuoka K, Bravo MR, Murano M, 2005. A revision of the genus Parastilomysis (Mysida: Mysidae), with descriptions of three new species and establishment of a new genus for P. secunda. Journal of Crustacean Biology, 25:31-48.

Ii N, 1936. Studies on Japanese Mysidacea II. Descriptions of three new species belonging to two new genera, Parastilomysis and Paracanthomysis. Japanese Journal of Zoology, 7:1-15.

Ii N, 1964. Fauna Japonica, Mysidae. Biogeographical Society of Japan, Tokyo, pp. 1-610.

Liu R, Wang S, 2000. Fauna Sinica, Arthropoda, Crustacea, Malacostraca, order Mysidacea. Science Press, Beijing, pp. 1-326 (in Chinese with English abstract).

Mauchline J, Murano M, 1977. World list of the Mysidacea, Crustacea. Journal of the Tokyo University of Fisheries, 64:39-88

Müller HG, 1993. World catalogue and bibliography of the recent Mysidacea. Wissenchaftlicher Verlag, Tropical Products Trading Center, Wetzlar, pp. 1-238.

Murano M, 1970a. A small collection of benthic Mysidacea from coastal waters in Suruga Bay, Japan. Crustaceana, 18:251-268. 
Murano M, 1970b. Systematic and ecological studies on Mysidacea collected by the bottom-net. Journal of the Oceanographical Society of Japan, 26:137-150.

Tattersall WM, Tattersall OS, 1951. The British Mysidacea. Ray Society, London, pp. 1-460.

Wang S, Liu R, 1997. Mysidacea fauna of the East China Sea.
Studia Marina Sinica, 38:191-222 (in Chinese with English abstract and description).
Received January 17, 2013

Revised July 5, 2013 Accepted July 8, 2013 